\title{
Impact of pylorus preservation on delayed gastric emptying after pancreaticoduodenectomy-analysis of 5,000 patients based on the German StuDoQ|Pancreas-Registry
}

\author{
Tim Fahlbusch ${ }^{1 \wedge}$, Andreas Minh Luu ${ }^{1}$, Philipp Höhn ${ }^{1}$, Carsten Klinger², Jens Werner ${ }^{3}$, Tobias Keck ${ }^{4}$, \\ Helmut Friess $^{5}$, Jörg Köninger ${ }^{6}$, Thomas Kraus ${ }^{7}$, Guido Alsfasser ${ }^{8}$, Winfried Padberg ${ }^{9}$, Jörg Peter Ritz ${ }^{10}$, \\ Waldemar $\mathrm{Uhl}^{1}{ }^{\wedge}$, Orlin Belyaev ${ }^{1 \wedge}$
}

${ }^{1}$ St. Josef Hospital, Department of General and Visceral Surgery, Ruhr-University Bochum, Germany; ${ }^{2}$ Deutsche Gesellschaft für Allgemeinund Viszeralchirurgie, Berlin, Germany; ${ }^{3}$ Department of General, Visceral, and Transplant Surgery, University Hospital Munich, LMU, Munich, Germany; ${ }^{4}$ Department of Surgery, University Hospital Schleswig-Holstein, Campus Lübeck, Lübeck, Germany; ${ }^{5}$ Klinik und Poliklinik für Chirurgie, Klinikum rechts der Isar, TUM München, Germany; ${ }^{6}$ Klinik für Allgemein-, Viszeral-, Thorax- und Transplantationschirurgie, Katharinenhospital, Stuttgart, Germany; ${ }^{7}$ Allgemein-, Viszeral- und Minimalinvasive Chirurgie, Nordwestkrankenhaus Frankfurt, Frankfurt am Main, Germany; ${ }^{8}$ Abteilung für Allgemein-, Viszeral-, Gefäß- und Transplantationschirurgie, Universitätsmedizin Rostock, Rostock, Germany; ${ }^{9}$ Allgemein-, Viszeral-, Thorax-, Transplantations- und Kinderchirurgie, Universitätsklinikum Gießen Marburg, Standort Gießen, Gießen, Germany; ${ }^{10}$ Klinik für Allgemein- und Viszeralchirurgie, Helios Kliniken Schwerin, Schwerin, Germany

Contributions: (I) Conception and design: T Fahlbusch, W Uhl, O Belyaev; (II) Administrative support: T Fahlbusch, W Uhl, O Belyaev; (III) Provision of study materials or patients: All authors; (IV) Collection and assembly of data: All authors; (V) Data analysis and interpretation: T Fahlbusch, W Uhl, O Belyaev; (VI) Manuscript writing: All authors; (VII) Final approval of manuscript: All authors.

Correspondence to: Orlin Belyaev, MD, PhD. Ruhr-University Bochum, Department of General and Visceral Surgery, St. Josef-Hospital, Gudrunstraße 56, 44791 Bochum, Germany. Email: orlin.belyaev@klinikum-bochum.de.

\begin{abstract}
Backgrounda Delayed gastric emptying (DGE) is one of the most common complications after pancreatic head resection. It leads to increased length of hospital stay, high costs for healthcare systems and reduced quality of life. The primary aim of the study was to assess the impact of pylorus preservation, respectively resection on the occurrence of DGE in patients undergoing pancreaticoduodenectomy (PD).

Methods: All cases of pylorus-resecting PD (PRPD) and pylorus-preserving PD (PPPD) entered in the StuDoQIPancreas nationwide registry of the German Society of General and Visceral Surgery from 01/01/2014 until 31/12/2018 including demographics, surgical techniques, histopathological and perioperative data were retrospectively analyzed. This study was approved by the ethics committee of the Ruhr-University Bochum, Germany.

Results: Data of 5,080 patients were enrolled. PPPD was the method of choice (70.4\%). Pylorus preservation had no impact on the occurrence of DGE (20.3\% vs. $21.5 \%, \mathrm{P}=0.33)$, but further risk factors could be identified. The comparison of PPPD and PRPD groups showed statistically significant differences in the surgical approach (primary open approach, 94.8\% vs. 98.0\%, $\mathrm{P}<0.001$ ), duration of surgery (326.4 vs. 352.1 minutes, $\mathrm{P}<0.001$ ), technique of pancreatic anastomosis (pancreaticojejunostomy $v s$. pancreaticojejunostomy), $78.6 \%$ vs. $85.2 \%, \mathrm{P}<0.001)$.

Conclusions: Patient factors, intraoperative factors, duration of surgery and postoperative factors (postoperative pancreatic fistula, biliary leakage and other surgical complications) were identified as risk factors for DGE. Future research should focus on register-based, prospective, randomised-controlled studies such as the currently recruiting "PyloResPres trial".
\end{abstract}

Keywords: Pancreatic head resection; registry; StuDoQ।Pancreas; pylorus preservation; delayed gastric emptying (DGE)

^ ORCID: Tim Fahlbusch, 0000-0002-2178-6685; Waldemar Uhl, 0000-0002-7719-3192; Orlin Belyaev, 0000-0002-0595-2292. 
Submitted Sep 23, 2021. Accepted for publication Dec 15, 2021.

doi: $10.21037 / g s-21-645$

View this article at: https://dx.doi.org/10.21037/gs-21-645

\section{Introduction}

Mortality after pancreatic surgery has been reduced significantly over the past decades. Experienced centers report mortality rates ranging from $0-6 \%(1,2)$. However, postoperative morbidity remains at a high level (3). Delayed gastric emptying (DGE) is one of the most common complications after pancreatic head resections and occurs in up to $80 \%$ of cases (4). DGE leads to increased length of hospital stay, high costs for healthcare systems, reduced quality of life (5) and a delay in adjuvant cancer treatment.

The International Study Group for Pancreatic Surgery (ISGPF) defined DGE by the number of days a nasogastric tube is required and solid food can be digested (6).

Surgical techniques, postoperative pancreatic fistulas (POPF), higher age, sepsis or intraabdominal abscesses are seen as risk factors for DGE, although conflicting results have been reported (7-9). Due to a lack of a causal therapy, the prevention of DGE is of major importance.

There is scarce data about the impact of DGE after major pancreatic surgery. Large study populations have not been examined yet and there is an unmet need for further knowledge about this clinically highly important issue.

The German Society of General and Visceral Surgery (DGAV) initiated a national registry (Studien-, Dokumentationsund Qualitätszentrum, StuDoQ) for pancreatic surgery in 2013 (StuDoQIPancreas), providing extensive information from German and foreign pancreatic surgery centers (10). Data about demographics, indications, types of procedures and perioperative outcome after pancreatic head resections have been gathered, retrospectively analysed and are reported on behalf of the nationwide registry. The aim of the study was to assess the impact of pylorus preservation, respectively resection on the occurrence of DGE in a large cohort of patients undergoing pancreaticoduodenectomy (PD). We present the following article in accordance with the STROBE reporting checklist (available at https://gs.amegroups.com/article/view/10.21037/ gs-21-645/rc).

\section{Methods}

\section{The StuDoQI Pancreas registry}

The DGAV established the nationwide StuDoQIPancreas registry for pancreatic diseases in order to assess the quality of pancreatic surgery in Germany. Data from more than 50 high volume pancreatic surgery centers are pseudonymized and retrospectively entered in an online tool. Written consent was given by all patients for evaluation in the registry. StuDoQ। Pancreas information was cross-checked with the hospitals' controlling data and annually certified. All cases of classic and pylorus-preserving PD entered in StuDoQI Pancreas from 01/01/2014 until 31/12/2018 including demographics, surgical techniques, histopathological and perioperative data have been analyzed. Patients with an unknown DGE status or who underwent a surgical procedure other than PPPD or PRPD were excluded from evaluation.

\section{Definitions}

PD was defined either as pylorus-resecting (PRPD, Kausch-Whipple-procedure) or pylorus-preserving (PPPD, Traverso-Longmire). Lymphadenectomy (LAD), DGE, postoperative pancreatic fistula (POPF), postpancreatectomy hemorrhage (PPH) and chyle leakage were analyzed according to the grading system of the International Study Group for Pancreatic Surgery (ISGPS) (6,11-14). Complications and morbidity were assessed using the Clavien-Dindo-Classification (15).

\section{Statistical analysis}

Calculations were performed using SPSS V21.0 (IBM Corp. Released 2015, IBMStatistics for Windows, Version 23.0. Armonk, NY: IBM Corp.) and WinPepi (Pepi-forWindows) (16). A two-sided significance level of 0.05 was applied. Scale variables were assessed by mean and range, categorical variables by absolute count and percentages.

Univariate analyses were performed using Student's $t$-test, Mann-Whitney-U, Kruskal-Wallis and chi $^{2}$-test. Statistically significant associations with DGE were also assessed in a multivariate logistic regression model.

\section{Ethical statement}

The study was conducted in accordance with the 
Table 1 Univariate analysis of patient characteristics of the PPPD and PRPD group; values are expressed by means and standard deviations

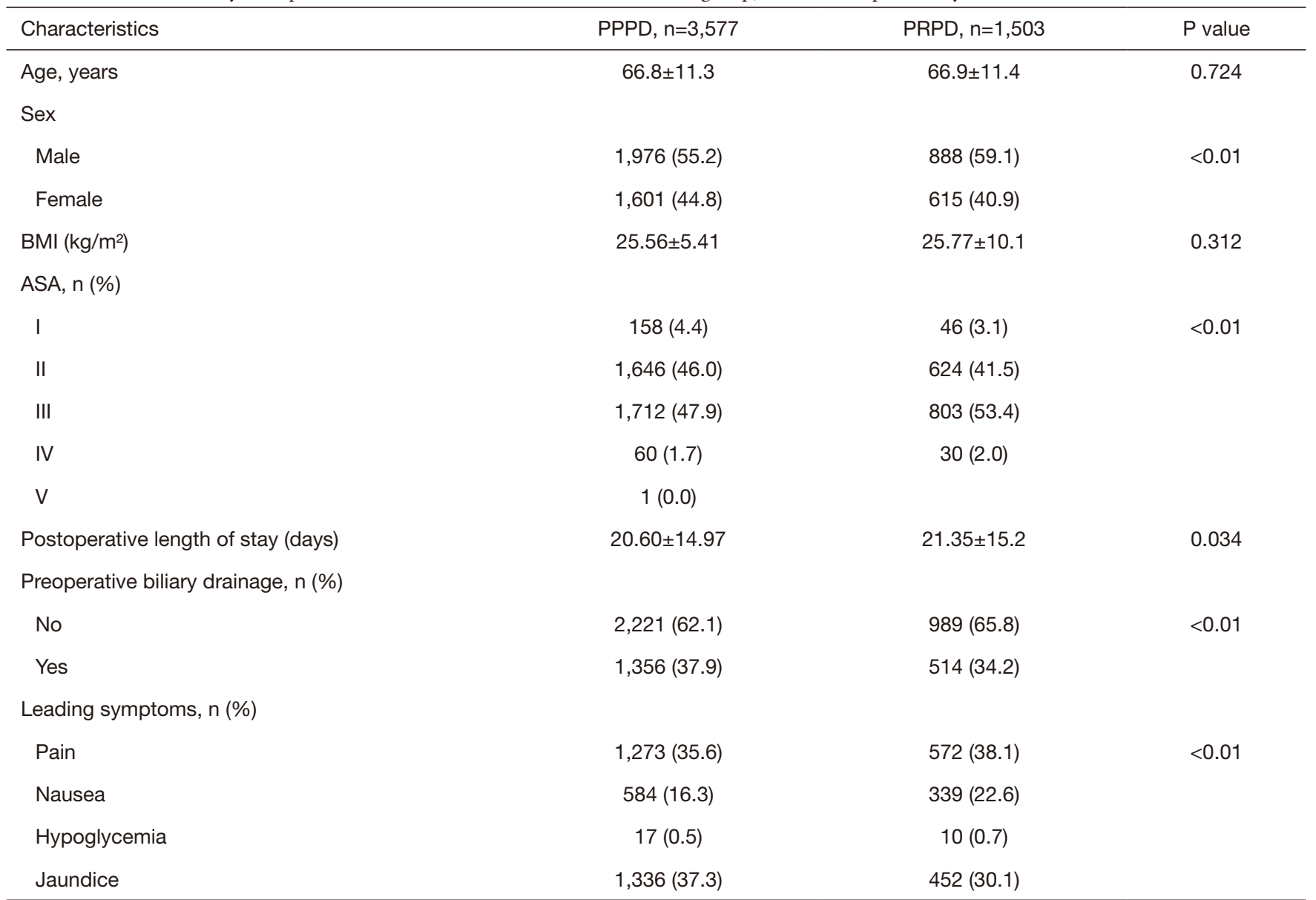

BMI, body mass index; ASA classification, American Society of Anesthesiologists; PRPD, pylorus-resecting pancreaticoduodenectomy; PPPD, pylorus-preserving pancreaticoduodenectomy.

Declaration of Helsinki (as revised in 2013). The study was approved by the ethics committee of the Ruhr-University Bochum, Germany (Reg. Nr. 20-7116-BR) and individual consent for this retrospective analysis was waived.

\section{Results}

Five thousand and eighty patients were enrolled. 2,864 $(56.4 \%)$ patients were male whereas females accounted for $43.6 \%(n=2,216)$. The mean age was $66.78 \pm 11.35$ years and the mean BMI $25.62 \pm 7.16 \mathrm{~kg} / \mathrm{m}^{2}$. The mean postoperative length of stay was $20.82 \pm 15.05$ days. 2,515 (49.5\%) patients were classified as ASA III or higher. Preoperative abdominal pain was the most common clinical symptom $(n=1,845$, $36.6 \%)$, followed by jaundice ( $\mathrm{n}=1,788,35.2 \%)$ and nausea $(\mathrm{n}=923,18.2 \%)$. The high amount of cholestasis led to the application of biliary stents in $36.8 \%(n=1,870)$ of patients. PPPD was the method of choice in the majority of patients (70.4\%). 3,577 PPPD and 1,503 PRPD were performed. The mean postoperative length of stay in ICU was $5.09 \pm 8.91$ days in the entire study population. Table 1 presents the comparison of PPPD and PRPD groups. Pylorus resection was more common in males, those without biliary drainage and in patients with higher ASA class and those suffering pain. It led to a prolonged hospital stay and nausea.

In the entire study population a conventional/open approach was chosen in $4,864(95.7 \%)$ of patients. Extended LADs were performed in $11.9 \%(\mathrm{n}=605)$ and pancreaticojejunostomies (PJ) in $80.6 \%(n=4,093)$ of pancreatic head resections. Synchronous resections of liver metastases were performed $112(2.2 \%)$ times. An overall 30-day-mortality of $4.1 \%(n=213)$ was reported. Most patients deceased within 30 days after surgery due 
Table 2 Univariate analysis of operative data of the PPPD and PRPD group

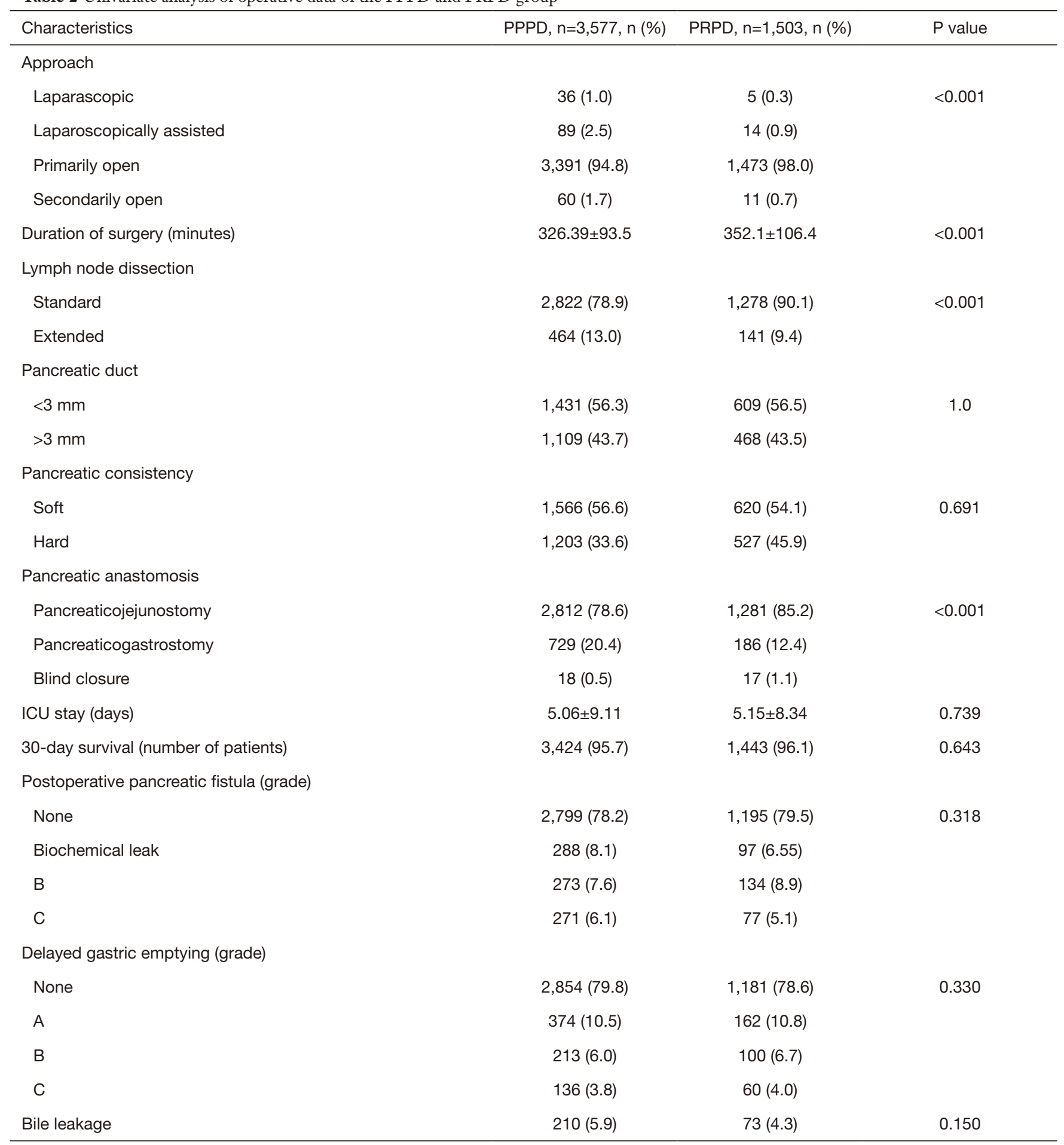

Table 2 (continued) 
Table 2 (continued)

\begin{tabular}{lcc}
\hline Characteristics & PPPD, $\mathrm{n}=3,577, \mathrm{n}(\%)$ & PRPD, $\mathrm{n}=1,503, \mathrm{n}(\%)$ \\
\hline Postpancreatectomy hemorrhage & & \\
None & $3,317(87.1)$ & $1,340(89.2)$ \\
A & $84(2.3)$ & $38(2.5)$ \\
B & $166(4.6)$ & $57(3.8)$ \\
C & $210(5.9)$ & $68(4.5)$ \\
\hline
\end{tabular}

ICU, intensive care unit; PRPD, pylorus-resecting pancreaticoduodenectomy; PPPD, pylorus-preserving pancreaticoduodenectomy.

Table 3 Univariate analysis of benign and malignant histopathological results

\begin{tabular}{|c|c|c|c|}
\hline Characteristics & PPPD, n (\%) & PRPD, n (\%) & $P$ value \\
\hline Pancreatic ductal adenocarcinoma & $1820(70.6)$ & $863(74.8)$ & 0.008 \\
\hline Ampullary carcinoma & $344(13.3)$ & $94(8.2)$ & $<0.001$ \\
\hline Bile duct carcinoma & $330(12.8)$ & $115(10.0)$ & 0.014 \\
\hline Intraductal papillary mucinous neoplasm carcinoma & $14(0.5)$ & $10(0.9)$ & 0.253 \\
\hline Cystadenocarcinoma & - & $3 / 0.2$ & \\
\hline Benign & $n=983$ & $n=283$ & \\
\hline Intraductal papillary mucinous neoplasm & $258(26.3)$ & $65(23.0)$ & 0.265 \\
\hline Pseudocyst & $15(1.5)$ & $7(2.5)$ & 0.283 \\
\hline Cystic pancreatic neuroendocrine neoplasm & $10(1.0)$ & $2(0.7)$ & 0.635 \\
\hline Benign tumours & $116(11.8)$ & $19(6.7)$ & 0.015 \\
\hline Chronic pancreatitis & $384(39.1)$ & $163(57.6)$ & $<0.001$ \\
\hline Other & $3(0.3)$ & $1(0.3)$ & 0.899 \\
\hline Pancreatic neuroendocrine neoplasm & $138(14.2)$ & - & \\
\hline
\end{tabular}

PRPD, pylorus-resecting pancreaticoduodenectomy; PPPD, pylorus-preserving pancreaticoduodenectomy.

to surgical complications $(49.8 \%, \mathrm{n}=103)$. Table 2 indicates surgical data for the PPPD and PRPD group.

Pylorus preservation was more common with minimally invasive-approach and associated with shorter duration of surgery and more extended lymph node dissections. The majority of patients received a PJ.

The most common resected neoplasm was a pancreatic ductal adenocarcinoma (PDAC). Table 3 demonstrates histopathological results: 3,436 malignant (67.3\%) and
1,644 (32.7\%) benign diagnoses were found.

PPPD was more common for ampullary and bile duct cancer, while it was less common for PDAC and duodenal cancer. A pylorus resection was more frequent in patients with chronic pancreatitis, while PPPD was the method of choice for benign tumours.

DGE occurred in $20.6 \%(\mathrm{n}=1,045)$ of all patients. Patients suffering from DGE stayed for $28.98 \pm 20.4$ postoperative days, whereas patients without DGE were discharged after 
Table 4 Multivariate comparison of DGE and non-DGE group

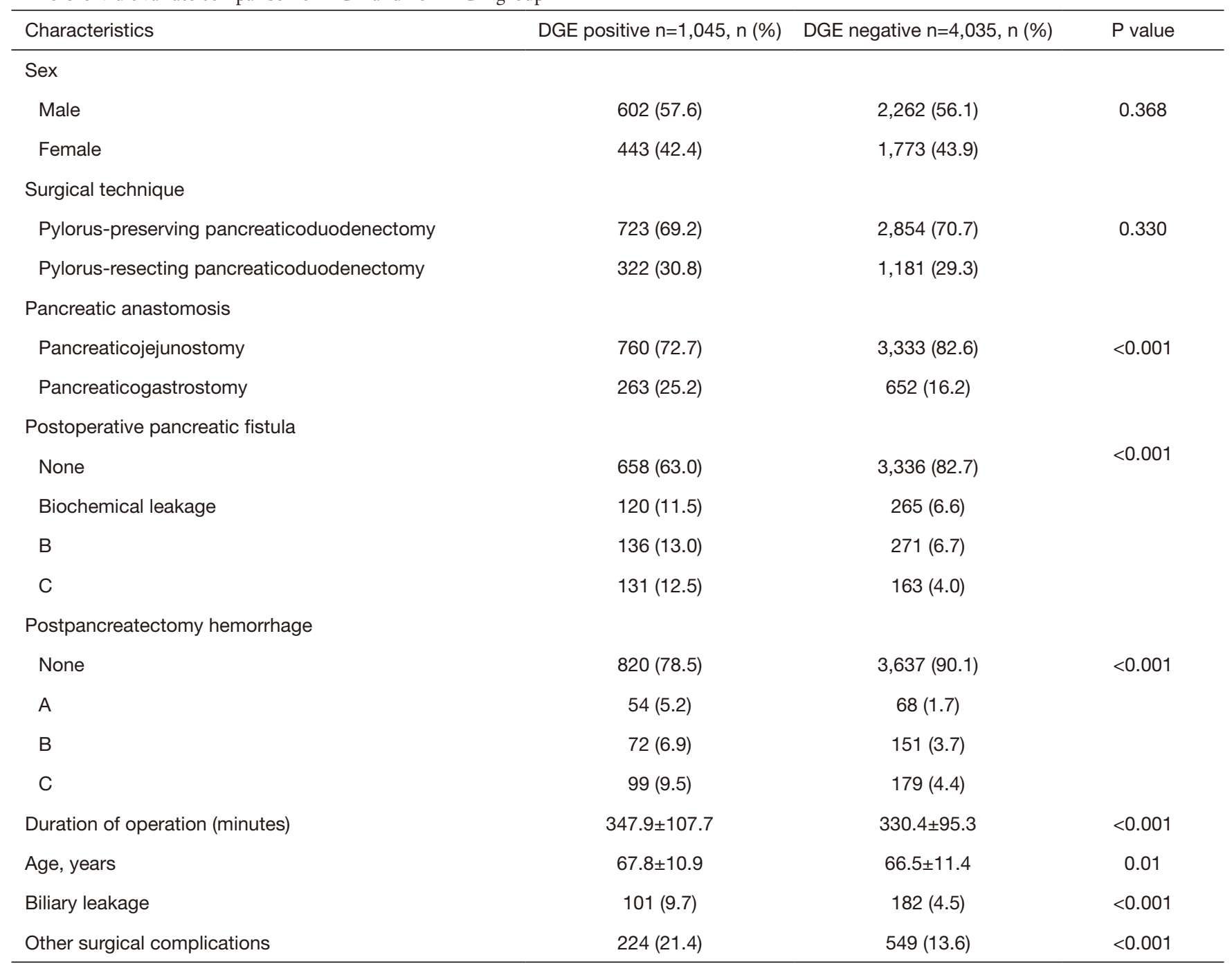

Other surgical complications: chyle leakage, pancreatic leakage, anastomotic stenosis, gastrointestinal bleeding, pancreatitis in the remnant. DGE, delayed gastric emptying.

$18.71 \pm 12.48$ days $(\mathrm{P}<0.001)$. DGE grade $\mathrm{A}$ was found in $10.6 \%(n=536)$, grade $B$ in $6.2 \%(n=313)$ and grade $C$ in $3.9 \%$ $(\mathrm{n}=196)$ of patients. DGE grade A led to a postoperative stay of $23.14 \pm 13.67$ days and grade B was associated with a stay of $28.82 \pm 26.88$ days. Patients suffering from DGE grade C were discharged after $45.22 \pm 29.98$ days $(\mathrm{P}<0.001)$. Table 4 highlights characteristics of patients with DGE.

Higher age and longer duration of surgery were associated with DGE. DGE also was more common in PG than in the PJ group. Over $25 \%$ of DGE patients had POPF, whereas less than $11 \%$ suffered from POPF in the non-DGE group. DGE patients developed PPH more often than non-DGE patients (21.5\% vs. 9.9\%). All types of postoperative complications were increased the DGE group: POPF, PPH, HJ leakage and others.

Univariate analysis revealed various characteristics that were associated with a statistically significant increase of the frequency of DGE. These characteristics were analysed in a multivariate logistic regression model. It revealed a statistically significant association with the occurrence of DGE for higher age $(\mathrm{P}=0.006)$, longer duration of surgery $(\mathrm{P}<0.001)$, reconstruction as $\mathrm{PG}(\mathrm{P}<0.001)$, POPF $(\mathrm{P}=0.001)$, insufficiency of $\mathrm{HJ}(\mathrm{P}<0.001)$ and other surgical complications $(\mathrm{P}=0.009)$. The results are found in Figure 1. 

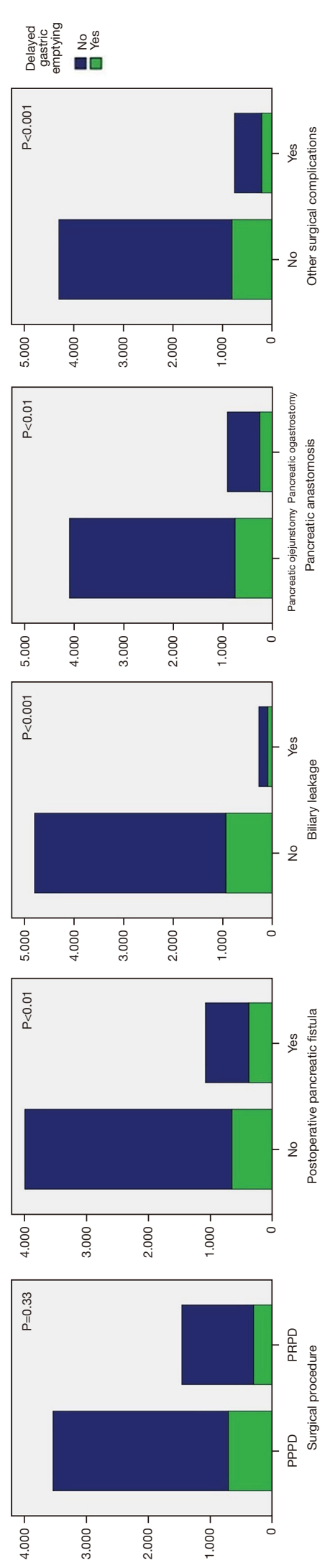

DGE occurs up to $80 \%$ of patients after pancreaticoduodenectomy and ranks as the most common complication $(4,17)$. It is accompanied by an increased length of hospital stay, higher costs for healthcare systems and reduced quality of life (5). The initiation of an adjuvant chemotherapy might be delayed which possibly exercises a negative influence on survival. The pathophysiology of DGE is not completely understood, although various attempts have been made to elucidate the mechanism. Ischemia and denervation of the stomach due the mobilization or lymphadenectomy, reduced motilin levels after duodenectomy or intraabdominal complications have been suspected causes (18). Propulsive medication such as off label use of erythromycin might attenuate DGE (19).

Currently, PPPD is the procedure of choice in contrast to the classic, pylorus-resecting operation. According to the literature it leads to reduced length of surgery, blood loss and equal complication rates $(20,21)$.

So far, literature data about DGE are mostly based on small numbers of patients or meta-analyses. In this study we are presenting data of 5,080 PD patients from the StuDoQI Pancreas registry of the DGAV. All patients were enrolled in high volume centers for pancreatic surgery. Due to the outstanding number of patients, the statistical analysis leads to high validity of the data.

In our study, the majority of pancreaticoduodenectomies were performed as pylorus-preserving operations. DGE occurred in $20.6 \%$ of patients, a rate that has also been shown by other groups (8). Whereas in the literature, a wide range of DGE from $5 \%$ up to $81 \%$ are reported $(4,17)$. In our study population, most cases showed a mild DGE (grade A, 10.6\%), which correlates to results in the literature (7). Half of all cases showed a mild DGE underlining the use of a standardized definition for DGE such as the applied ISGPS definition.

After uni- and multivariate analyses higher age, a longer duration of surgery, reconstruction as PG, POPF, insufficiency of $\mathrm{HJ}$ and other surgical complications can be seen as risk factors for DGE. According to our data avoiding a reconstruction as PG and a longer duration of surgery could decrease the frequency of DGE, whereas a high patients' age or the occurrence of complications can scarcely be influenced in practice.

Parmar and coauthors stated only postoperative complications as POPF, sepsis and the need for reoperation to be associated with DGE (8). Mohammed et al. listed 
intraabdominal abscesses as an additional risk factor, which was not validated in our study population. Histological results were not associated with higher DGE rates according to results in the literature (9). Hüttner et al. found a statistically significant association of PPPD and DGE in a meta-analysis (21). Klaiber et al. described inconclusive results in their meta-analysis of randomized controlled trials, whereas the German PROPP-trial showed no advantage of PRPD in relation to DGE in a prospective single center study $(22,23)$. The present data reveal no statistical difference in this context $(20.2 \%$ vs. $21.4 \%$, $\mathrm{P}=0.330)$. $\mathrm{PG}$ and $\mathrm{PJ}$ were shown to be associated with the same frequency of DGE in a large prospective randomized trial (2). Our registry data show a higher rate of DGE cases in the PG group. Werba et al. analyzed the registry of the NSQIP collaborative and also identified risk factors for DGE. Among others, they found concurrent adhesiolysis, feeding jejunostomy or a vascular reconstruction with vein graft to be associated with DGE. Age and postoperative complications were also enumerated (24). Inconsistent results might be caused by differing local operational techniques, enrolled patients or varying recorded variables in each registry. We do include a large number of patients in this registry study, however there are data, which the registry is not able to provide.

The reconstruction techniques using a single or double loop for the hepatojejunostomy, the addition of a Billroth II (BII) or Roux-en-Y technique for the gastrojejunostomy, antecolic or retrocolic reconstruction have not been specified in the registry. The pancreatic anastomosis technique has neither been tracked. Therefore an inclusion of these technical details was not feasible in our study, even though at other occasions these factors have shown to be of relevance for DGE. In Germany the duct-to-mucosa-pancreaticojejunostomy is widely spread, although various variations are used [Blumgart, Heidelberg technique $(25,26)]$. Hartwig et al recommended an antecolic route to reduce the occurrence of DGE (27). Yang et al. found a lower frequency of DGE after a BII reconstruction (28). A Braun enterostomy should follow a BII reconstruction in order to attenuate DGE (29). In the registry rare complications (e.g., chyle leakage, pancreatic leakage, anastomotic stenosis, gastrointestinal bleeding or pancreatitis in the remnant) are summed up as "other surgical complications", impeding a precise evaluation

Even though all data were included in the registry in a prospective fashion, all data have been evaluated retrospectively. Randomized controlled trials addressing the impact of DGE are scarce (30). Therefore, the DGAV has already initiated a prospective, randomized controlled, multicenter, register-based study entitled "PyloResPres-Trial" (DRKS00018842). This registry based RCT trial might enable more insights into the mechanism of DGE, have impact on the technique of pancreatic head resections and offer a decrease of occurrence of this common complication after PD.

The StuDoQ-registry created the unique opportunity to analyze the data of more than 5,000 patients who underwent a pancreatic head resection. Higher age, longer duration of surgery, reconstruction as PG, POPF, insufficiency of $\mathrm{HJ}$ and other surgical complications were identified as risk factors leading to DGE. Future research should focus on large, register-based, prospective randomised-controlled trials. The PyloResPres trial is a promising attempt to gather more information about this important complication of pancreatic surgery and its results will be awaited with interest.

\section{Acknowledgments}

The results of this paper have previously been presented at the German Congress on Surgery (138. Deutscher Chirurgenkongress, April 10th 2021 , "Die postoperative Magenentleerungsstörung in der Pankreaschirurgie - eine retrospektive StuDoQ-basierte Analyse von 5000 pyloruserhaltenden und resezierenden Pankreaskopfresektionen"). We thank our colleagues for providing data for the StuDoQIPancreas-Registry: Ghadimi M, Mees ST, Reißfelder C, Anthuber M, Bartsch D, Nüssler N, Hartwig W, Schnitzbauer A, Glanemann M, Gutt C, Köninger J, Kraus T, Oldhafer KJ, Germer CT, Kalff JC, Mönch C, Fichtner-Feigl S, Farkas S, Piso P, Grützmann R, Tröbs U, Adam U, Niedergethmann M, Pascher A, Bektas H, Tschmelitsch J, Hommann M, Reith HB, Kroesen AJ, Nies C, Bruns C, Chromik AM, Klammer F, Jäger M, Lammers BJ, Wagler Elke, Lorenz EPM, Rudolph H, Pauthner M, Prenzel K, Schäfer N, Krüger CM, Illert B, Mittelkötter U, Kindler M, Döhrmann A, Kaiser GM, Schmeding M, Schwarzbach M, Hartmann J, Stavrou G, Krones C, Jacobi T, Homayounfar K, Scherwitz P, Wilhelm T, Frommhold K, Hesse U, Pratschke J. Funding: None.

\section{Footnote}

Reporting Checklist: The authors have completed the STROBE reporting checklist. Available at https:// 
gs.amegroups.com/article/view/10.21037/gs-21-645/rc

Data Sharing Statement: Available at https://gs.amegroups. com/article/view/10.21037/gs-21-645/dss

Peer Review File: Available at https://gs.amegroups.com/ article/view/10.21037/gs-21-645/prf

Conflicts of Interest: All authors have completed the ICMJE uniform disclosure form (available at https://gs.amegroups. com/article/view/10.21037/gs-21-645/coif). The authors have no conflicts of interest to declare.

Ethical Statement: The authors are accountable for all aspects of the work in ensuring that questions related to the accuracy or integrity of any part of the work are appropriately investigated and resolved. The study was conducted in accordance with the Declaration of Helsinki (as revised in 2013). The study was approved by the ethics committee of the Ruhr-University Bochum, Germany (Reg. Nr. 20-7116-BR) and individual consent for this retrospective analysis was waived.

Open Access Statement: This is an Open Access article distributed in accordance with the Creative Commons Attribution-NonCommercial-NoDerivs 4.0 International License (CC BY-NC-ND 4.0), which permits the noncommercial replication and distribution of the article with the strict proviso that no changes or edits are made and the original work is properly cited (including links to both the formal publication through the relevant DOI and the license). See: https://creativecommons.org/licenses/by-nc-nd/4.0/.

\section{References}

1. van Heek NT, Kuhlmann KFD, Scholten RJ, et al. Hospital volume and mortality after pancreatic resection: a systematic review and an evaluation of intervention in the Netherlands. Ann Surg 2005;242:781-8, discussion 788-90.

2. Keck T, Wellner UF, Bahra M, et al. Pancreatogastrostomy Versus Pancreatojejunostomy for RECOnstruction After PANCreatoduodenectomy (RECOPANC, DRKS 00000767): Perioperative and Long-term Results of a Multicenter Randomized Controlled Trial. Ann Surg 2016;263:440-9.

3. Schmidt CM, Turrini O, Parikh P, et al. Effect of hospital volume, surgeon experience, and surgeon volume on patient outcomes after pancreaticoduodenectomy: a singleinstitution experience. Arch Surg 2010;145:634-40.

4. Bell R, Pandanaboyana S, Shah N, et al. Meta-analysis of antecolic versus retrocolic gastric reconstruction after a pylorus-preserving pancreatoduodenectomy. HPB (Oxford) 2015;17:202-8.

5. Hayama S, Senmaru N, Hirano S. Delayed gastric emptying after pancreatoduodenectomy: comparison between invaginated pancreatogastrostomy and pancreatojejunostomy. BMC Surg 2020;20:60.

6. Wente MN, Bassi C, Dervenis C, et al. Delayed gastric emptying (DGE) after pancreatic surgery: a suggested definition by the International Study Group of Pancreatic Surgery (ISGPS). Surgery 2007;142:761-8.

7. Glowka TR, Webler M, Matthaei H, et al. Delayed gastric emptying following pancreatoduodenectomy with alimentary reconstruction according to Roux-en-Y or Billroth-II. BMC Surg 2017;17:24.

8. Parmar AD, Sheffield KM, Vargas GM, et al. Factors associated with delayed gastric emptying after pancreaticoduodenectomy. HPB (Oxford) 2013;15:763-72.

9. Mohammed S, van Buren Ii G, McElhany A, et al. Delayed gastric emptying following pancreaticoduodenectomy: Incidence, risk factors, and healthcare utilization. World J Gastrointest Surg 2017;9:73-81.

10. Wellner UF, Klinger C, Lehmann K, et al. The pancreatic surgery registry (StuDoQ। Pancreas) of the German Society for General and Visceral Surgery (DGAV) presentation and systematic quality evaluation. Trials 2017;18:163.

11. Tol JAMG, Gouma DJ, Bassi C, et al. Definition of a standard lymphadenectomy in surgery for pancreatic ductal adenocarcinoma: a consensus statement by the International Study Group on Pancreatic Surgery (ISGPS). Surgery 2014;156:591-600.

12. Bassi C, Marchegiani G, Dervenis C, et al. The 2016 update of the International Study Group (ISGPS) definition and grading of postoperative pancreatic fistula: 11 Years After. Surgery 2017;161:584-91.

13. Wente MN, Veit JA, Bassi C, et al. Postpancreatectomy hemorrhage (PPH): an International Study Group of Pancreatic Surgery (ISGPS) definition. Surgery 2007;142:20-5.

14. Besselink MG, van Rijssen LB, Bassi C, et al. Definition and classification of chyle leak after pancreatic operation: A consensus statement by the International Study Group on Pancreatic Surgery. Surgery 2017;161:365-72.

15. Dindo D, Demartines N, Clavien PA. Classification of 
surgical complications: a new proposal with evaluation in a cohort of 6336 patients and results of a survey. Ann Surg 2004;240:205-13.

16. Abramson JH. WINPEPI (PEPI-for-Windows): computer programs for epidemiologists. Epidemiol Perspect Innov 2004;1:6.

17. Eshuis WJ, van Eijck CHJ, Gerhards MF, et al. Antecolic versus retrocolic route of the gastroenteric anastomosis after pancreatoduodenectomy: a randomized controlled trial. Ann Surg 2014;259:45-51.

18. Lytras D, Paraskevas KI, Avgerinos C, et al. Therapeutic strategies for the management of delayed gastric emptying after pancreatic resection. Langenbecks Arch Surg 2007;392:1-12.

19. Yeo CJ, Barry MK, Sauter PK, et al. Erythromycin accelerates gastric emptying after pancreaticoduodenectomy. A prospective, randomized, placebo-controlled trial. Ann Surg 1993;218:229-37; discussion 237-8.

20. Tani M, Terasawa H, Kawai M, et al. Improvement of Delayed Gastric Emptying in PylorusPreserving Pancreaticoduodenectomy: Results of a Prospective, Randomized, Controlled Trial. Ann Surg 2006;243:316-20.

21. Hüttner FJ, Fitzmaurice C, Schwarzer G, et al. Pyloruspreserving pancreaticoduodenectomy (pp Whipple) versus pancreaticoduodenectomy (classic Whipple) for surgical treatment of periampullary and pancreatic carcinoma. Cochrane Database Syst Rev 2016;2:CD006053.

22. Klaiber U, Probst P, Strobel O, et al. Meta-analysis of delayed gastric emptying after pylorus-preserving versus pylorus-resecting pancreatoduodenectomy. Br J Surg 2018;105:339-49.

Cite this article as: Fahlbusch T, Luu AM, Höhn P, Klinger C, Werner J, Keck T, Friess H, Köninger J, Kraus T, Alsfasser G, Padberg W, Ritz JP, Uhl W, Belyaev O. Impact of pylorus preservation on delayed gastric emptying after pancreaticoduodenectomy-analysis of 5,000 patients based on the German StuDoQIPancreas-Registry. Gland Surg 2022;11(1):67-76. doi: 10.21037/gs-21-645
23. Hackert T, Probst P, Knebel P, et al. Pylorus Resection Does Not Reduce Delayed Gastric Emptying After Partial Pancreatoduodenectomy: A Blinded Randomized Controlled Trial (PROPP Study, DRKS00004191). Ann Surg 2018;267:1021-7.

24. Werba G, Sparks AD, Lin PP, et al. The PrEDICT-DGE score as a simple preoperative screening tool identifies patients at increased risk for delayed gastric emptying after pancreaticoduodenectomy. HPB (Oxford) 2021. [Epub ahead of print]. doi: 10.1016/j.hpb.2021.06.417.

25. Shrikhande SV, Kleeff J, Büchler MW, et al. Pancreatic anastomosis after pancreaticoduodenectomy: how we do it. Indian J Surg 2007;69:224-9.

26. Popp FC, Bruns CJ. Variationsbreite der Pankreatojejunostomie bei Pankreaskopfresektion. Chirurg 2017;88:3-10.

27. Hartwig $W$, Werner J, Jäger D, et al. Improvement of surgical results for pancreatic cancer. Lancet Oncol 2013;14:e476-e485.

28. Yang J, Wang C, Huang Q. Effect of Billroth II or Rouxen-Y Reconstruction for the Gastrojejunostomy After Pancreaticoduodenectomy: Meta-analysis of Randomized Controlled Trials. J Gastrointest Surg 2015;19:955-63.

29. Xu B, Zhu YH, Qian MP, et al. Braun Enteroenterostomy Following Pancreaticoduodenectomy: A Systematic Review and Meta-Analysis. Medicine (Baltimore) 2015;94:e1254.

30. Akizuki E, Kimura Y, Nobuoka T, et al. Prospective nonrandomized comparison between pyloruspreserving and subtotal stomach-preserving pancreaticoduodenectomy from the perspectives of DGE occurrence and postoperative digestive functions. J Gastrointest Surg 2008;12:1185-92. 